\title{
A Model of Chrysanthemum Stem Elongation
}

\author{
Meriam G. Karlsson ${ }^{1}$ and Royal D. Heins \\ Department of Horticulture, Michigan State University, East Lansing, MI 48824-1325
}

Additional index words. Chrysanthemum morifolium, Dendranthema grandiflora, height control

\begin{abstract}
The relative progression of lateral shoot elongation from pinch to flower of chrysanthemum [Dendranthema grandiflora (Ramat.) Kitamura 'Bright Golden Anne'] plants grown under 2 to $22 \mathrm{~mol}^{\cdot} \mathrm{day}^{-1} \cdot \mathrm{m}^{-2}$ photosynthetic photon flux and 10 to 20C was modeled using Richards function. Parameters for the function were determined by first transforming data of shoot length and time from pinch (start of short photoperiods) to flower to a relative scale of 0.0 to 1.0 by dividing all intermediate shoot lengths and measurement dates by final shoot length and number of days to flower, respectively. Data used for parameter estimation originated with plants grown at a daily average of $\leq \mathbf{2 0 C}$, since those grown at a daily average above $20 \mathrm{C}$ exhibited delayed morphological flower induction and reached $50 \%$ of the final shoot length earlier in development. Relative shoot elongation was described by Richards function in the following form: Relative shoot length $=S_{F} \times\left\{1+\left[\left(S_{F} / S_{O}\right)^{N}-1\right] \times e^{-S_{F} K t}\right\}^{-1 / N}$ where $t$ (relative time) $=0.0$ to $1.0, S_{F}$ (maximum relative shoot length $)=1.018, S_{0}($ relative shoot length at $t=0)=0.0131, N($ model parameter related to the shape of the curve $)=0.3923$, and $K$ (model parameter related to mean relative growth rate) $=\mathbf{5 . 8 1 3 8}$.
\end{abstract}

Many floriculture crops are marketed using a predetermined date and height specification. Proper application of height-control techniques, such as the use of growth retardants (Mastalerz, 1977) and temperature control between the day and night (Heins and Erwin, 1990), is required to produce plants that comply with the height specifications of the market.

Time-related growth processes in plants often are represented by functions describing sigmoid curves. Sigmoid curves are bounded by two horizontal asymptotes and always have a positive first derivative (Causton and Venus, 1981). Growth adhering to a sigmoid pattern initially exhibits a lag phase with little or unobservable growth, followed by a grand, or log, phase characterized by rapid growth, and finally an asymptotic phase of slow or no growth. Sigmoid-pattern growth in terms of number, length, height, or overall size and weight includes that found in bacterial cells, leaves, fruits, internodes, and whole plants (Hunt, 1982; Klein and Klein, 1988; Wareing and Phillips, 1981). Lateral shoot growth of determinate-flowering species also follows sigmoid growth.

Examples of nonlinear, asymptotic functions describing sigmoidal growth include the logistic, Gompertz, and Richards. The logistic growth curve has been used extensively in animal ecology for modeling the change in numbers of individuals in a population, and in the plant sciences for analyzing plant growth (Hunt, 1982). The Gompertz function was developed from work with animals and population studies and has the three coefficients of the independent variables arranged as a double exponent (Causton and Venus, 1981; Draper and Smith, 1981; Erickson, 1976; Hunt, 1982; Richards, 1959; Richards, 1969; Winsor, 1932). Growth of plant parts, especially leaves, has been described by the Gompertz function (Hunt, 1982). Both the logistic and Gompertz functions have fixed inflection points relative to the two asymptotes. In contrast, the inflection point of a Richards growth curve is determined as the coefficients are estimated and is variable in location on the curve. This variability allows much flexibility in describing

Received for publication 1 June 1993. Accepted for publication 29 Oct. 1993. The authors acknowledge the support of the Michigan Agriculture Experiment Station, the American Floral Endowment, and the Fred C. Gloeckner Foundation. The cost of publishing this paper was defrayed in part by the payment of page charges. Under postal regulations, this paper therefore must be hereby marked advertisement solely to indicate this fact.

${ }^{1}$ Current address: Department of Plant, Animal and Soil Sciences, University of Alaska Fairbanks, Fairbanks, Alaska 99775-7200. growth patterns. The Richards function often gives a good representation of plant growth.

Chrysanthemum [Dendranthema grandiflora (Ramat.) Kitamura] is a short-day plant. The commercial production sequence consists of long-day (LD) growth, apical decapitation (pinching), and either immediate short-day (SD) growth or a LD period followed by SD. Flowers develop under SD on the determinate lateral shoots formed after pinch (Crater, 1992).

Larsen and Gertsson (1992) modeled the effects of daily light integral and the relationship between day and night temperature on shoot elongation of chrysanthemum 'Garland'. This model is limited to the growing conditions of 8-h photoperiod, daily average of $18 \mathrm{C}$, and a thermoperiod that was not synchronized with the photoperiod. Retarding chrysanthemum shoot elongation by daminozide application has also been modeled (Larson and Lieth, 1993; Lieth and Larson, 1993). This model (Larson and Lieth, 1993; Lieth and Larson, 1993) was based on the use of a modified Richards function to predict the daily increment of shoot growth after daminozide application. Widespread application of the model is limited because its parameters are based solely on the cultivar 'Bright Golden Anne', grown under one set of day and night temperatures.

Proper control of lateral-shoot elongation is essential to produce plants of desired market specifications. If the progression of shoot elongation during the production period from pinch to flower could be described by a general model for any cultivar and final plant height, actual plant height could be compared continuously to expected height. Deviations from the predicted pattern of shoot elongation could then be detected early enough in crop development to allow modifications in cultural techniques and assure desired final plant height. Any model should be sufficiently robust to predict the desired progression of lateral shoot length for cultivars that require different durations to flower and for plants that have different final height specifications. This paper describes such a model.

\section{Materials and Methods}

The data to develop the stem-elongation curve were based on lateral shoot development in chrysanthemum 'Bright Golden Anne' grown under a range of environmental conditions. Rooted cuttings were planted in $10-\mathrm{cm}\left(500 \mathrm{~cm}^{3}\right)$ pots filled with a commercial peat-lite medium (Baccto Pro Plant Mix, Michigan Peat Co., Houston). Plants were placed in growth chambers under 
LD at a photosynthetic photon flux (PPF) of $325 \mu \mathrm{mol} \cdot \mathrm{m}^{-2} \cdot \mathrm{s}^{-1}(16$ $\left.\mathrm{h} \cdot \mathrm{day}^{-1}, 18.7 \mathrm{~mol} \cdot \mathrm{day}^{-1} \cdot \mathrm{m}^{-2}\right)$ at $20 \mathrm{C}$ day and night. Plants were pinched to six nodes after seven days and placed under SD (10-h light, 14-h dark) in one of 15 treatments. Treatments were arranged in a three-factor [PPF, day temperature (DT), and night temperature (NT)] central composite statistical design (Gardiner et al., 1967). The studied ranges for the factors were 50 to $600 \mu \mathrm{mol}$. $\mathrm{m}^{-2} \cdot \mathrm{s}^{-1}\left(10 \mathrm{~h} \cdot \mathrm{day}^{-1}, 1.8\right.$ to $\left.21.6 \mu \mathrm{mol} \cdot \mathrm{day}^{-1} \cdot \mathrm{m}^{-2}\right)$ for PPF and 10 to $30 \mathrm{C}$ for both DT and NT; other growth and developmental data from plants in these experiments have been previously published (Karlsson et al., 1989a; Karlsson and Heins, 1992). Treatments throughout will be described in the form PPF-DT-NT, e.g. $325-20-20$ for the $325 \mu \mathrm{mol} \cdot \mathrm{m}^{-2} \cdot \mathrm{s}^{-1} \mathrm{PPF}$ and $20 \mathrm{DT}$ and $20 \mathrm{NT}$ treatment.

Stem-length measurements of the second lateral shoot were made on five randomly selected plants every 10 days until flowering, which was defined as the time at which the outermost petals were reflexed horizontally (Karlsson, 1987). The second lateral
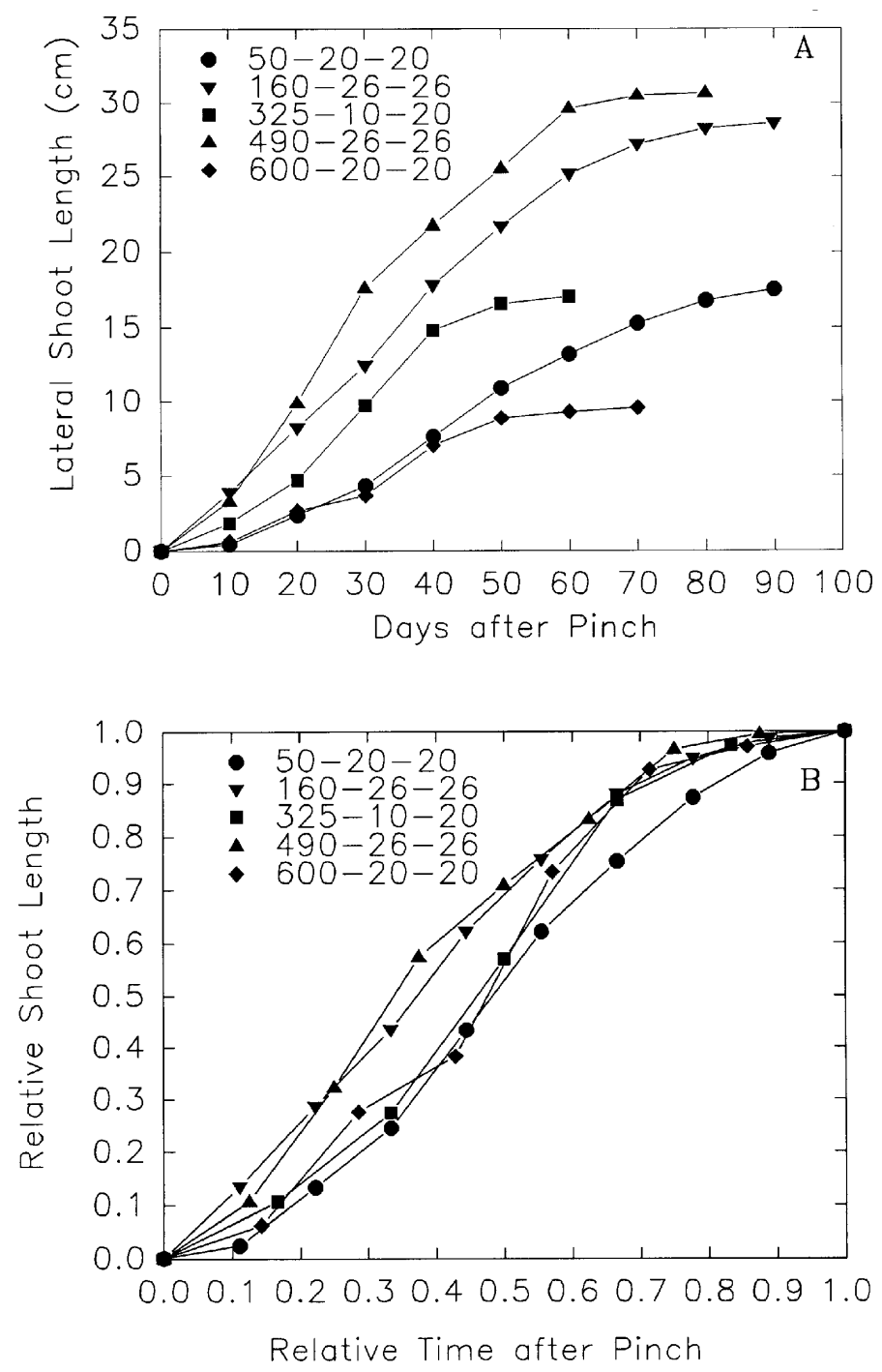

Fig. 1. Stem-elongation progression curves in Dendranthema grandiflora 'Bright Golden Anne' from start of short days to flower. Axis scaling based on (A) actual time and height and $(\mathbf{B})$ relative time (first short day set to 0.0 and flowering to 1.0) and relative height (shoot length at flowering set at 1.0). Treatment codes on graphs represent combinations of photosynthetic photon flux $\left(\mathrm{PPF}, \mathrm{mol} \cdot \mathrm{m}^{-2} \cdot \mathrm{s}^{-1}\right)$, day temperature (DT, C), and night temperature (NT, C) indicated as PPF-DTNT. shoot was chosen because it exhibited the most developmental uniformity.

Time to flower and shoot length varied greatly among treatments (Fig. 1A). To facilitate comparison of the shoot-elongation progression without interference from the variable flowering times and final shoot lengths, the data were transformed to relative scales from 0.0 to 1.0. The day of pinch (first SD) was assigned 0.0 and flowering, 1.0; shoot length at pinch was assigned 0.0 and at flowering, 1.0 (Fig. 1B). All other data points were linearly scaled between 0.0 and 1.0. Some variation in curve shape was still apparent. The cause was evaluated by comparing relative time to $50 \%$ of final stem length and shoot-leaf number with the average daily temperature of the treatments. A subset of treatments consisting of those in which the daily average was $\leq 20 \mathrm{C}$ was selected for model development. The Richards function (Richards, 1959, 1969) was chosen to model stem elongation using the following form:

Relative shoot length $=\mathrm{S}_{\mathrm{F}} \times\left\{1+\left[\left(\mathrm{S}_{\mathrm{F}} / \mathrm{S}_{\mathrm{O}}\right)^{\mathrm{N}}-1\right] \times \mathrm{e}^{-\mathrm{S}_{\mathrm{F}} \mathrm{Kt}}\right\}^{-1 / \mathrm{N}}$

where $\mathrm{t}$ is relative time from 0.0 to $1.0, \mathrm{~S}_{\mathrm{F}}$ is the maximum relative shoot length $(S), S_{O}$ is the value of $S$ at $t=0$, and $K$ and $N$ are model parameters related to the mean relative growth rate and the shape of the curve (Lieth and Carpenter, 1990).

The parameters of the Richards function $\left(\mathrm{S}_{\mathrm{F}}, \mathrm{S}_{\mathrm{O}}, \mathrm{N}\right.$, and $\left.\mathrm{K}\right)$ were estimated by fitting equation (1) to transformed data using the derivative-free nonlinear regression procedure (PROC NLIN) of PC/SAS (SAS Institute, 1989). Parameters were estimated for data from each treatment in the subset and for pooled data from all subset treatments.

Comparison of Eq. [1] efficacy using parameters from the pooled data vs. parameters from individual treatments was determined by comparing predicted values from each set of parameters with the original untransformed data. This was done by multiplying relative time and predicted relative height values by treatment days to flower and final heights, respectively.

Using parameters from the pooled data, Eq. [1] was used to develop graphs which can be used for height-control decision support in the commercial production of chrysanthemum.

\section{Results and Discussion}

Time to flower under SD varied from 60 days for plants grown in the 600-20-20 treatment to 90 days for plants grown in the 50-20-20, 160-26-26, or 325-30-20 treatments (Karlsson et al., 1989b). Final lateral shoot length at flowering varied from $10 \mathrm{~cm}$ for plants grown in the 325-10-20 treatment to $34 \mathrm{~cm}$ for plants grown in the 160-26-14 treatment (Karlsson et al., 1989a).

Figure 1A shows the progression of stem elongation from pinch to flowering for plants grown in five representative environments. Irrespective of environmental treatment and resulting time to flower and final height, lateral shoot development followed a sigmoid growth pattern. Curves were more similar when the variation in development time and shoot lengths was eliminated by transforming time and lengths to relative scales (Fig. 1B). However, curves did not follow an identical pattern from pinch to flower, and relative time required to reach $50 \%$ of final height still varied from 0.34 to 0.48 (Table 1 ).

The differences in relative time to $50 \%$ final length were related to treatment temperature conditions. No statistical relationship between PPF and relative time to 50\% final length was observed $\left(r^{2}=0.05\right)$. Instead, relative time to reach $50 \%$ final length depended on the average daily temperature (ADT) during plant development (Fig. 2). As ADT increased, less relative time was 
Table 1. Relative time (start of short days set to 0.0 and flowering to 1.0 ) required to reach $50 \%$ of the shoot length at flowering for Dendranthema grandiflora 'Bright Golden Anne' grown at 15 combinations of photosynthetic photon flux (PPF), day temperature (DT) and night temperature (NT).

\begin{tabular}{ccccc}
\hline \hline $\begin{array}{l}\text { PPF } \\
\left(\mu \mathrm{mol} \cdot \mathrm{m}^{-2} \cdot \mathrm{s}^{-1}\right)\end{array}$ & $\begin{array}{c}\text { DT } \\
(\mathrm{C})\end{array}$ & $\begin{array}{c}\text { NT } \\
(\mathrm{C})\end{array}$ & $\begin{array}{c}\text { Avg daily } \\
\text { temp }(\mathrm{C})\end{array}$ & $\begin{array}{c}\text { Relative time to } \\
50 \% \text { final length }\end{array}$ \\
\hline 50 & 20 & 20 & 20.0 & 0.48 \\
160 & 14 & 14 & 14.0 & 0.47 \\
160 & 14 & 26 & 21.0 & 0.44 \\
160 & 26 & 14 & 19.0 & 0.44 \\
160 & 26 & 26 & 26.0 & 0.37 \\
325 & 20 & 10 & 14.2 & 0.44 \\
325 & 10 & 20 & 15.8 & 0.48 \\
325 & 20 & 20 & 20.0 & 0.41 \\
325 & 30 & 20 & 24.2 & 0.35 \\
325 & 20 & 30 & 25.8 & 0.42 \\
490 & 14 & 14 & 14.0 & 0.47 \\
490 & 14 & 26 & 21.0 & 0.39 \\
490 & 26 & 14 & 19.0 & 0.40 \\
490 & 26 & 26 & 26.0 & 0.34 \\
600 & 20 & 20 & 20.0 & 0.46 \\
Mean relative time to 50\% length & & 0.42 \\
\hline
\end{tabular}

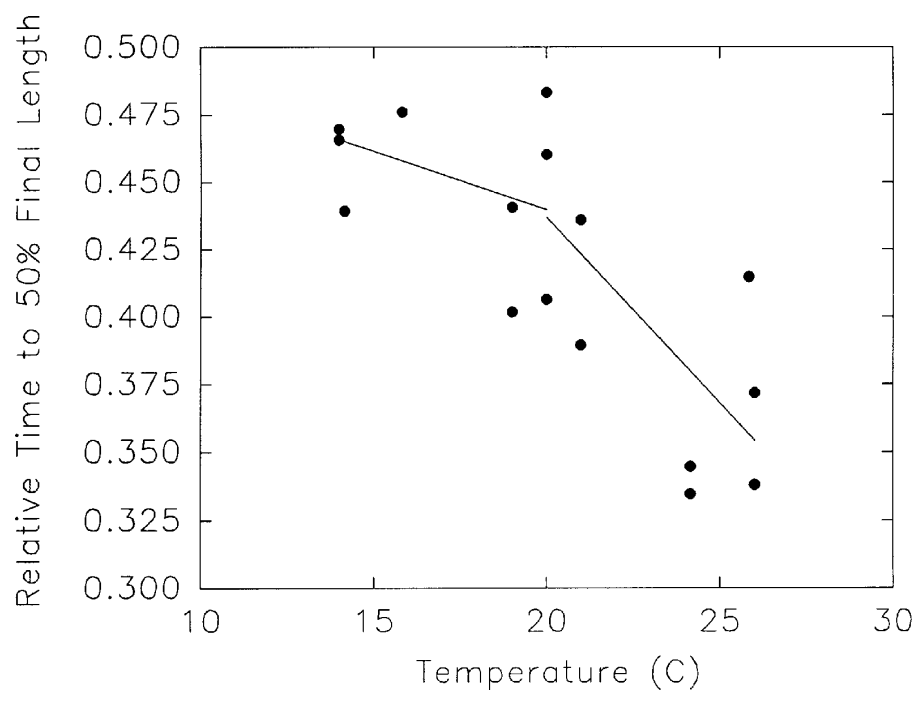

Fig. 2. Relative time (first short day set to 0.0 and flowering to 1.0) required to attain $50 \%$ of the shoot length at flowering as influenced by average daily temperature during plant development for Dendranthema grandiflora 'Bright Golden Anne'. The function for temperatures of 14 to $20 \mathrm{C}$ was relative height $=0.51-0.0036 \times$ temperature $\left(r^{2}=0.11\right)$ and for temperatures of 20 to $26 \mathrm{C}$ was relative height $=$ $0.71-0.014 \times$ temperature $\left(r^{2}=0.50\right)$.

required to reach 50\% final shoot length, especially above 20C. Similarly, less relative time was required to reach $50 \%$ final shoot length as shoot leaf number at flower increased (Fig. 3). Plants with a higher shoot leaf number (those grown at ADT > 20C) required more time to complete the second half of stem elongation than those whose shoots had a lower leaf number. The longer relative time to complete the second half of stem elongation is probably related to the slower flower development that occurs at higher than optimal temperatures; optimal temperature is near 20C (De Jong, 1978; De Lint and Heij, 1987; Karlsson et al., 1989b, 1989c; Pearson, et al., 1993).

Absolute growth curves in Figure 4A represent the stem elongation of plants grown in the nine treatments with ADT of $20 \mathrm{C}$ or

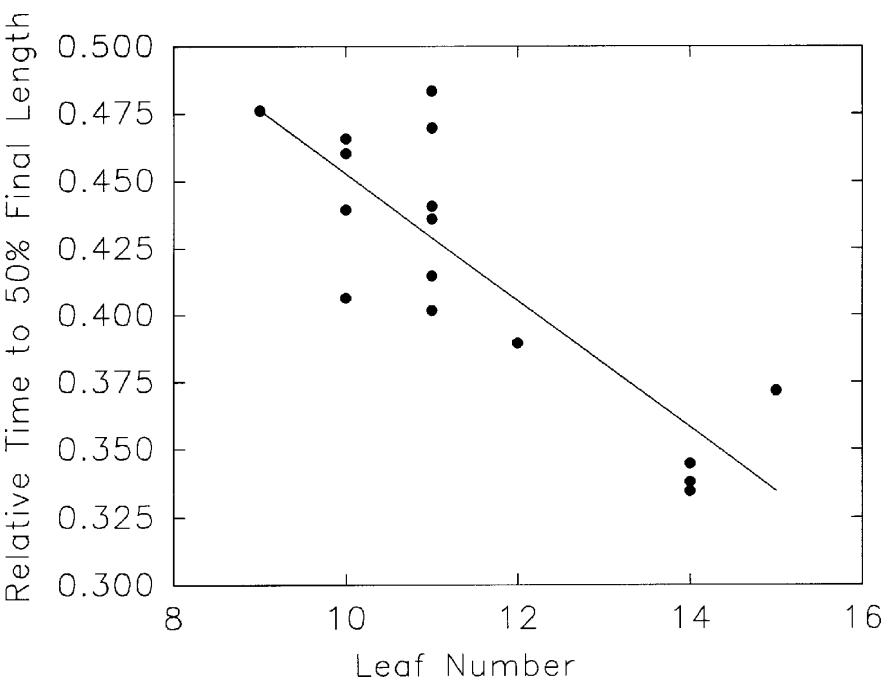

Fig. 3. Relative time (first short day set to 0.0 and flowering to 1.0 ) required to attain $50 \%$ of the shoot length at flowering as influenced by shoot leaf number at flowering for Dendranthema grandiflora 'Bright Golden Anne'. The function for temperatures of 14 to $20 \mathrm{C}$ was relative height $=0.69-0.0236 \times$ leaf number $\left(r^{2}\right.$ $=0.71$ ).
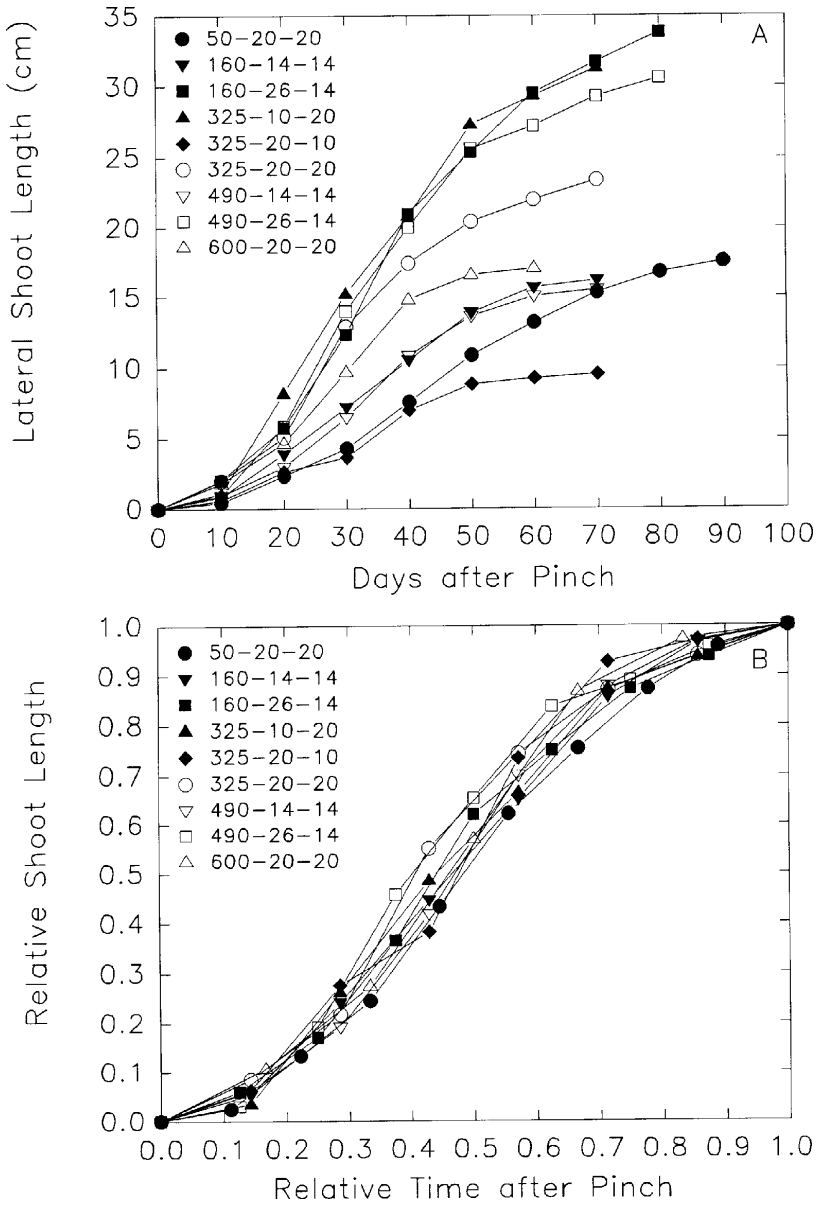

Fig. 4. Stem-elongation curves in Dendranthema grandiflora 'Bright Golden Anne' from start of short days to flower of plants growing in treatment combinations in which the daily average was $20 \mathrm{C}$ or lower. Axis scaling based on (A) actual time and height and $(\mathbf{B})$ relative time (first short day set to 0.0 and flowering to 1.0 ) and relative height (shoot length at flowering set at 1.0). Treatment codes on graphs represent combinations of photosynthetic photon flux (PPF, $\mu \mathrm{mol} \cdot \mathrm{m}^{-2}$. $\mathrm{s}^{-1}$ ), day temperature (DT, C), and night temperature (NT, C), indicated as PPFDT-NT. 

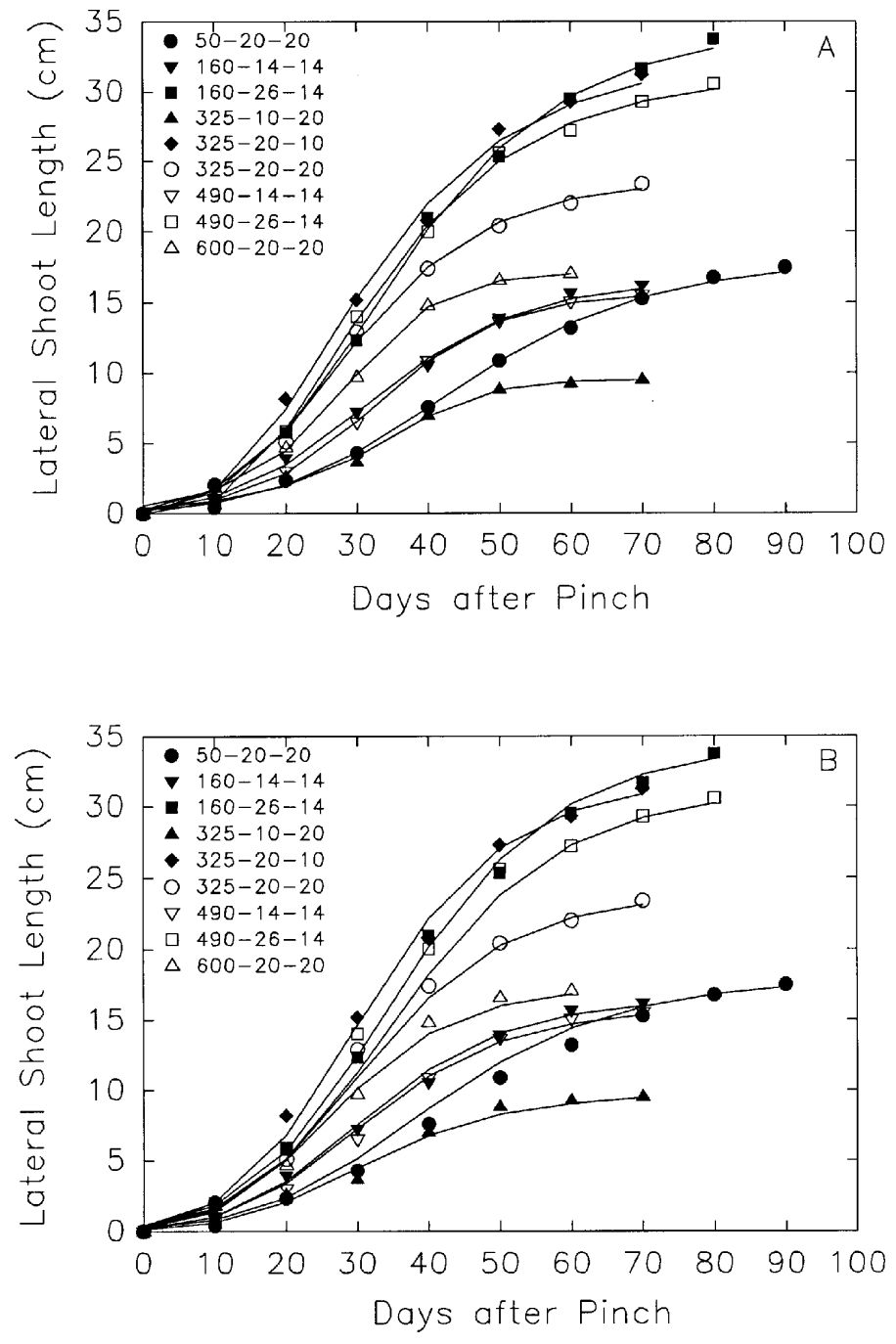

Fig. 5. Predicted stem-elongation curves (as lines) based on [Eq. 1] compared with actual data values (as symbols). Parameters from Table 2 used to calculate prediction lines based on (A) individual-treatment parameter estimates and (B) combined-data parameter estimates.

Table 2. Parameter estimates, $R^{2}$, and residual sum of squares for Richards function [Eq. 1] on relative shoot elongation (shoot length at flowering set to 1.0) vs. relative time (first short day set to 0.0 and flowering to 1.0) in Dendranthema grandiflora 'Bright Golden Anne' grown at nine combinations of photosynthetic photon flux $\left(\mathrm{PPF}, \mu \mathrm{mol} \cdot \mathrm{m}^{-2} \cdot \mathrm{s}^{-1}\right)$, day temperature (DT, C), and night temperature (NT, C), indicated as PPF-DT-NT, and the pooled data of all nine treatments.

\begin{tabular}{|c|c|c|c|c|c|c|}
\hline \multirow[b]{2}{*}{ Description } & \multicolumn{3}{|c|}{ Parameter } & \multicolumn{3}{|c|}{ Statistics } \\
\hline & $\mathrm{S}_{\mathrm{F}}$ & $\mathrm{S}_{\mathrm{O}}$ & $\mathrm{N}$ & $\mathrm{K}$ & $R_{2}$ & $\mathrm{SS}^{\mathrm{z}}$ \\
\hline $50-20-20$ & 1.025 & 0.013 & 0.4156 & 5.4398 & 0.999 & 2.3 \\
\hline $160-14-14$ & 1.023 & 0.018 & 0.4710 & 5.6498 & 0.998 & 3.9 \\
\hline $160-26-14$ & 1.018 & 0.009 & 0.2151 & 5.2389 & 0.999 & 18.5 \\
\hline $325-20-10$ & 1.032 & 0.001 & -0.0675 & 4.4357 & 0.997 & 4.1 \\
\hline $325-10-20$ & 0.999 & 0.041 & 2.0769 & 11.6344 & 0.993 & 9.7 \\
\hline $325-20-20$ & 1.011 & 0.006 & 0.1891 & 5.6895 & 0.998 & 3.0 \\
\hline $490-14-14$ & 1.101 & 0.017 & 0.8212 & 7.4994 & 0.999 & 5.3 \\
\hline $490-26-14$ & 1.019 & 0.000 & -0.1596 & 4.9692 & 0.999 & 1.3 \\
\hline $600-20-20$ & 1.005 & 0.032 & 2.4131 & 9.4131 & 0.999 & 1.4 \\
\hline Pooled data & 0.018 & 0.0131 & 0.3923 & 5.8138 & 0.994 & 82.2 \\
\hline
\end{tabular}

${ }^{\mathrm{z}}$ Residual sum of squares $\times 10^{-3}$

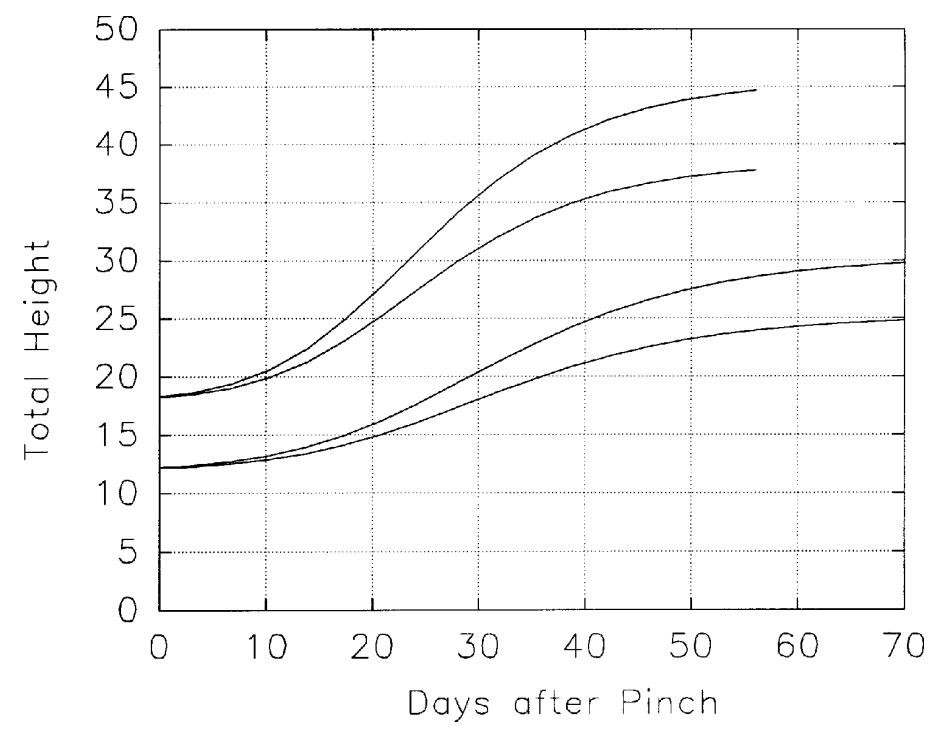

Fig. 6. Example curves created from [Eq. 1] and pooled data parameters. The upper two curves depict desired plant height from pinch to flower 56 days later, while the lower two curves depict desired total plant height from pinch to flower 70 days later. Initial starting and ending heights are typical for plants produced in $15-\mathrm{cm}$ pots (upper) and 11-cm pots (lower).

lower. Transformation of the absolute growth curves to relative units results in very similar curves, with relative time to $50 \%$ final length ranging from 0.40 to 0.48 (Fig. 4B). We therefore decided to develop a generalized stem-elongation curve based on plants grown at an ADT of $\leq 20 \mathrm{C}$.

The regressions of the Richards function on the shoot-length data from each selected treatment gave a very close fit, resulting in $R^{2}$ values of 0.993 to 0.999 (Table 2). Regression of the Richards function on the pooled shoot-length data from all selected treatments also gave a good fit, resulting in an $R^{2}$ of 0.994 . Parameters from the individual treatment regressions closely predicted heights over time (Fig. 5A) as expected from the high $R^{2}$ values (Table 2). Inspection of Figure 5B shows that the parameters from the pooled data model predict shoot length over time almost as well as parameters from the nine individual treatment regressions (Fig. 5A). Linear correlation $\left(r^{2}\right)$ between actual and predicted height was 0.998 for the individual treatment parameters and 0.995 for the pooled data parameters.

Lieth and Carpenter (1990) developed a predictive stem-elongation model for Easter lily (Lilium longiflorum Thunb). Plants were grown in environments with averages of 16,20 , or $23 \mathrm{C}$ until flowering, or were shifted during early leaf-unfolding phase from 16 to $23 \mathrm{C}$ or from 23 to $16 \mathrm{C}$ and allowed to flower. In modeling the stem elongation, they concluded that the overall shape of the stemelongation curves for the plants did not change significantly. Similarly, we conclude that the overall shape of the stem-elongation curve of chrysanthemum growing at $\leq 20 \mathrm{C}$ is similar and can be predicted by Richards function (Eq. 1) with parameter values of $\mathrm{S}_{\mathrm{F}}$ $=1.018, \mathrm{~S}_{\mathrm{O}}=0.0131, \mathrm{~N}=0.3923$, and $\mathrm{K}=5.8138$.

The normalized stem-elongation curve can be used to create graphs useful for tracking actual plant height throughout development to produce plants with a desired height. Based on the generalized function, an elongation curve can be calculated based on expected production time and desired plant height at flower. The curve is created by multiplying intermediate values of relative time by the expected number of days to flower and the corresponding calculated values of relative height by the final desired height. Figure 6 shows two sets of curves of desired lateral-shoot elongation for chrysanthemum plants. In the top set of curves, plants are 
expected to flower in 56 days (an 8-week response group cultivar) with a height specification of 38 to $45 \mathrm{~cm}$ (20- to $28-\mathrm{cm}$ final shoot length). In the bottom set, plants are expected to flower in 70 days (a 10-week response group cultivar) with a height specification of 25 to $30 \mathrm{~cm}$ (12.5- to $17.5-\mathrm{cm}$ final shoot length).

Graphing actual heights regularly over time allows continuous comparisons between actual and desired plant heights. The practice also provides an indication of the elongation rate during development. Timely and relevant modifications in cultural-control measures can be determined by comparing elongation rates and actual heights with expected elongation rates and expected heights. Plants with rapidly growing lateral shoots can be exposed to measures that slow shoot elongation, such as lower day than night temperatures, i.e., negative DIF (Heins and Erwin, 1990), or application of a growth retardant (Heins and Carlson, 1990). Similarly, plants with lateral shoots shorter than graph-predicted lengths can be exposed to warmer day than night temperatures (positive DIF) (Heins and Erwin, 1990). Either reduction or promotion of lateral shoot elongation can be initiated while plant height is still close to the expected absolute-height schedule so that the final height meets specifications.

The generalized stem-elongation curve was based on growth of 'Bright Golden Anne'. Although 'Bright Golden Anne' is classified as a tall-growing cultivar (Yoder Brothers, 1991), our experience has shown that the generalized stem-elongation curve is also applicable to shorter chrysanthemum cultivars. The relative stemelongation curve can be scaled appropriately to accommodate cultivars with different response times, i.e., different days to flower from start of short days (Fig. 6). The attribute of scaling makes this model superior to previous models (Larsen and Gertsson, 1992; Larsen and Lieth, 1993) that are not readily adaptable to the development of a decision-support tool.

Growing conditions with high temperatures that resulted in delayed morphological flower initiation altered the pattern of shoot elongation in chrysanthemum (Fig. 2). Estimated relative time to $50 \%$ length was 0.44 using the selected elongation function. Tracking the elongation of shoots for plants with delayed morphological flower initiation to the selected elongation model would be imprecise. The faster relative increase in lateral shoot length on these plants permits a comparatively larger absolute length than the function-value height during early development. Efforts to maintain shoot length at the lower values suggested by the selected function could result in short plants because the potential for additional stem elongation lessens as the flower matures. Therefore, some caution is advisable in practical implementation of the relative-elongation model, especially under high-temperature climatic conditions. However, the generalized stem-elongation function has been used successfully to commercially produce chrysanthemums with specific heights (Heins and Carlson, 1990). Several commercial greenhouse operations are utilizing the generalized stem-elongation function in graphical tracking as part of their plant-height management program (Kuack, 1990).

\section{Literature Cited}

Causton, D.R. and J.C. Venus. 1981. The biometry of plant growth. Edward Arnold, London.

Crater, G.D. 1992. Potted chrysanthemums, p. 249-287. In: R.A. Larson (ed.). Introduction to floriculture. 2nd ed. Academic Press, New York. De Lint, P.J.A.L. and G. Heij. 1987. Effects of day and night temperature on growth and flowering of chrysanthemum. Acta Hort. 125:101-110. De Jong, J. 1978. Selection for wide temperature adaptation in Chrysanthemum morifolium (Ramat.) Hemsl. Netherlands J. Agr. Sci. 26:110 118.

Draper, N.R. and H. Smith. 1981. Applied regression analysis. 2nd ed. Wiley, New York.

Erickson, R.O. 1976. Modeling of plant growth. Annu. Rev. Plant Physiol. 27:407-434.

Gardiner, D.A., R.G. Cragle, and P.T. Chandler. 1967. The response surface method as a biological tool. Tenn. Agr. Expt. Sta. Bul. 429:25-40.

Heins, R.D. and W.H. Carlson. 1990. Understanding and applying graphical tracking: A road map for growth. Greenhouse Grower 8(5):73-77.

Heins, R.D. and J. Erwin. 1990. Understanding and applying DIF-Here's how to use this powerful production tool. Greenhouse Grower 8:73-78.

Hunt, R. 1982. Plant growth curves. The functional approach to plant growth analysis. Edward Arnold, London.

Karlsson, M.G. 1987. Characterization of development and growth responses to irradiance and temperature for model development in chrysanthemum. PhD Diss., Michigan State Univ. East Lansing.

Karlsson, M.G., R.D. Heins, J.E. Erwin, R.D. Berghage, W.H. Carlson, and J.A. Biernbaum. 1989a. Temperature and photosynthetic photon flux influence chrysanthemum shoot development and flower initiation under short-day conditions. J. Amer. Soc. Hort. Sci. 114:158-163.

Karlsson, M.G., R.D. Heins, J.E. Erwin, R.D. Berghage, W.H. Carlson, and J.A. Biernbaum. 1989b. Irradiance and temperature effects on time of development and flower size in chrysanthemum. Scientia Hort. 39:257-267.

Karlsson, M.G., R.D. Heins, J.E. Erwin, and R.D. Berghage. 1989c. Development rate during four phases of chrysanthemum growth as determined by preceding and prevailing temperature. J. Amer. Soc. Hort. Sci. 114:234-240.

Karlsson, M.G. and R.D. Heins. 1992. Chrysanthemum dry matter partitioning patterns along irradiance and temperature gradients. Can. J. Plant Sci. 72:307-316.

Klein, R.M and D.T. Klein. 1988. Fundamentals of plant science, p. 318 320. Harper \& Row Publisher, New York.

Kuack, D.L. 1990. Growers on graphical tracking. Greenhouse Grower 8(5):78-80.

Larsen, R. and U. Gertsson. 1992. Model analysis of shoot elongation in chrysanthemum. Scientia Hort. 49:277-289.

Larsen, R.U. and J.H. Lieth. 1993. Shoot elongation retardation owing to daminozide in chrysanthemum: I. Modeling single applications. Scientia Hort. 53:109-127.

Lieth, J.H. and P. Carpenter. 1990. Modeling stem elongation and leaf unfolding of Easter lily during greenhouse forcing. Scientia Hort. 44:149-162.

Lieth, J.H. and R.U. Larsen. 1993. Shoot elongation retardation owing to daminozide in chrysanthemum: II. Modeling multiple applications. Scientia Hort. 53:17-139.

Mastalerz, J.W. 1977. The greenhouse environment. Wiley, New York. Pearson, S., P. Hadley, and A. E. Wheldon. 1993. A reanalysis of the effects of temperature and irradiance on time to flowering in chrysanthemum (Dendranthema grandiflora). J. Hort. Sci. 68:89-97.

Richards, F.J. 1959. A flexible growth function for empirical use. J. Expt. Bot. 10:290-300.

Richards, F.J. 1969. The quantitative analysis of growth. p. 3-76. In F.C. Steward (ed.). Plant physiology: a treatise. VA. Analysis of growth: behavior of plants and their organs. Academic Press, London.

SAS Institute, Inc. 1989. SAS/STAT user's guide. Ver. 6. Vol. 2. 4th ed. Cary, N.C.

Wareing, P.F. and I.D.J. Phillips. 1981. Growth and differentiation in plants, 3rd ed., p. 40-45. Pergamon Press, Oxford.

Winsor, C.P. 1932. The Gompertz curve as a growth curve. Proc. Natl. Acad. Sci. USA 18:1-7.

Yoder Brothers, Inc. 1991. Pot mum variety guide. Yoder Brothers, Barberton, Ohio. 